\title{
OPTIMIZATION OF AN INTEGRAL FLAT PLATE COLLECTOR-STORAGE SYSTEM FOR DOMESTIC SOLAR WATER HEATING IN ADANA
}

\author{
İbrahim Halil YILMAZ * \\ Department of Automotive Engineering, Adana Science and Technology University, Adana, Turkey
}

\begin{abstract}
In this paper, the optimum orientation and sizing of a thermosyphon flat plate collector-storage solar water heating system were determined using the typical meteorological year data for Adana, Turkey. The typical meteorological year data for the location was taken from Meteonorm software, and the daily hot water consumption was estimated by utilizing the Rand hot water profile. A transient modeling was carried out for the prediction of a full year system performance through the use of the System Advisor Model simulation program. The effects of the collector area, the storage tank volume, the daily average delivery temperature and the daily hot water consumption on the annual solar fraction were analyzed by the presented simulation model. Results showed that the optimum tilt angle for a due south-facing solar collector is found to be $35.0^{\circ}$ for maximizing the annual solar fraction. The collector area and storage tank size greater than $3 \mathrm{~m}^{2}$ and $100 \mathrm{~L}$ respectively have little effect on the solar utilization.
\end{abstract}

Keywords: Solar water heating, Flat plate collector, Optimum sizing, System Advisor Model, Adana

\section{INTRODUCTION}

Water heating which is one of the essentials of human beings requires thermal energy. This energy had been met by primitive methods such as burning of wood in the ancient times. The idea of heating water with solar energy dates back around 200 b.c. when the Rome empire got used it for heating the public baths [1]. Commercial use of solar water heating (SWH) in houses was invented toward the end of 19th century. This system was renovated in the following years through a set of improvements such as antifreeze, thermosyphon, heating control, etc. Today's world uses widely solar thermal technologies. By the end of 2014, an installed capacity of $410.2 \mathrm{GW}_{\text {th }}$ was in operation worldwide [2]. Figure 1 illustrates the global share of solar thermal technologies by 2014. In Turkey, water collectors like flat plate collectors (FPCs) were predominant with $80.80 \%$, followed by evacuated tube collectors (ETCs) with $19.17 \%$, and the rest was occupied by air collectors. The main issue why the FPCs are mostly used in the country is considered to be its cheapness relative to the ETCs.

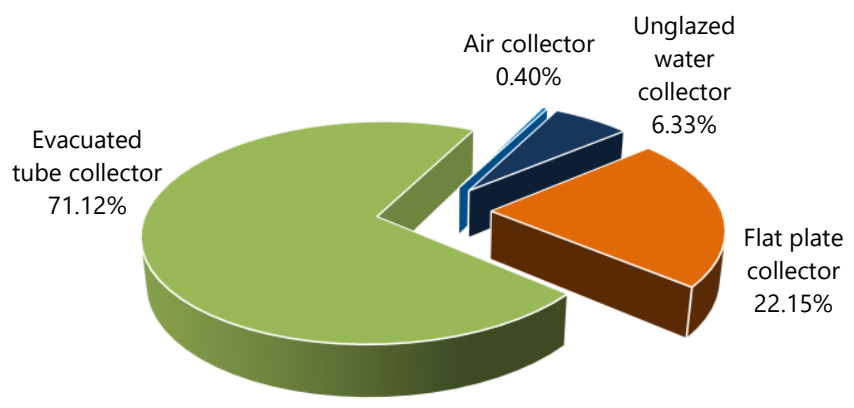

Figure 1. Distribution of the total installed capacity in operation by collector type. Adapted from [2]

*Corresponding Author: iyilmaz@adanabtu.edu.tr 
The levelized cost of energy (LCOE) for small thermosyphon domestic hot water systems ranges between 2-5 Euro-cent/kWh in Turkey [2]. The FPC systems are widely used in Turkey due to their lower capital cost relative to the ETC systems. A reduction in initial capital cost of solar thermal system is expected with the reduction in the capacity of the system components doing the same task. In order to reduce the LCOE of a specified FPC system, the parameters such as tilt angle, collector area, and volume of the storage tank have great significance and priority. Selection of the optimum values promotes efficient harnessing of solar energy with minimum capital cost and size.

A number of studies were carried out to find the optimum tilt angle for solar collectors in Turkey such as İzmir [3, 4], Adana, Ankara, Diyarbakır, Erzurum, İstanbul, İzmir, Samsun and Trabzon in [5]. These studies optimized the tilt angle for the associated locations based on the maximization of monthly average global radiation. Ertekin et al. [6] made a techno-economic analysis where the optimum tilt angles for 129 geographic locations of Turkey were found to maximize the useful heat gain by a SWH system. However, this study considered the determination of the energy requirements for water heating using the spatial interpolation method of universal kriging in ArcGIS software [7].

On the size modeling of SWH system for domestic supplies in Turkey is quite limited in the literature. Akinoğlu et al. [8] presented the modeling of a thermosyphon solar water heater in TRNSYS software [9] for the determination of the optimum collector area in the nine geographic locations of Turkey including İskenderun, Dalaman, İzmir, İstanbul, Sinop, Rize, Kayseri, Mardin, and Muş. In this model, the estimated monthly average daily global solar radiation for each location was used for running the transient simulations. Çomaklı et al. [10] carried out a transient modeling for a SWH system operating under the climatic conditions of Erzurum. The optimum size for the storage tank volume to collector area was proposed to be $50-70 \mathrm{~L} / \mathrm{m}^{2}$ for more economic and efficient solar water heating systems.

The literature review clearly indicates that a few studies dealt with the size optimization of SWH system in different parts of Turkey but the case study for Adana is still a question. It should be aware that in most of the SWH applications in Turkey, the implementers apply standard sizes for their installations which may not constantly comprise the optimum size. On the other hand, the use of a typical weather data for a location is usually required in many energy calculations. The main objective of this study is to determine the optimum tilt angle and size for SWH system in Adana which is one of the hottest cities in Turkey. For this reason, a long-term transient simulation is performed to analyze the optimum size of the SWH system using the typical meteorological year (TMY) data for Adana.

\section{MATERIALS AND METHODS}

\subsection{System Description}

A schematic of the SWH system for domestic supply is shown in Figure 2. It consists of a thermosyphon FPC connected with an insulated water storage tank (WST) in horizontal position. The FPC transfers solar energy from the collector fluid to the delivery water heated in the WST tank. Although water-ethylene glycol is often used as a collector fluid in FPCs which operates under the outdoor temperature below freezing, it was considered to be water in this study. Because the long-term measurements reveal that the lowest ambient temperature in Adana was over the freezing temperature. 


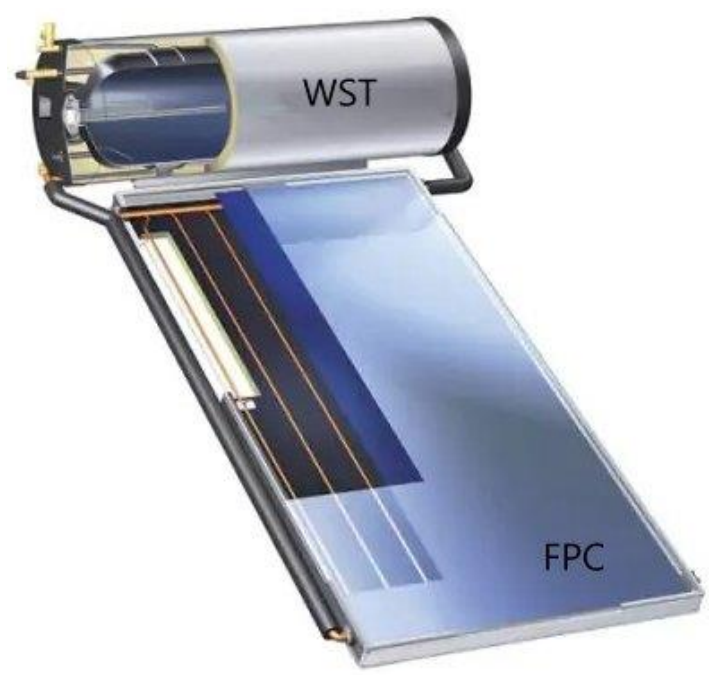

Figure 2. A SWH system with FPC and WST

\subsection{Collector Specifications}

The horizontal arrangement of the WST was analyzed in this study since they are more commonly used relative to the vertical ones in Turkey. But it should be known that the effect of the arrangement on the collector performance is almost negligible [11]. In other words, there is no difference in case the vertical WST is analyzed instead of the horizontal one. The technical specifications and the performance ratings of the FPC used in the simulation were taken from the database of Solar Rating \& Certification Corporation [12]. Table shows the characteristics of the FPC.

Table. Collector specifications [12]

\begin{tabular}{cc}
\hline Collector type & Glazed flat plate \\
Solar collector & Baymak Advanced X \\
Test fluid & Water \\
Test mass flow rate & $0.0188 \mathrm{~kg} / \mathrm{s} \cdot \mathrm{m}^{2}$ \\
$F_{R} \tau \alpha$ & 0.711 \\
$F_{R} U_{L}$ & $4.757 \mathrm{~W} / \mathrm{m}^{2} .^{\circ} \mathrm{C}$ \\
Incidence angle modifier, $b_{0}$ & $-0.1535\left(1^{\mathrm{st}}\right.$ order coeff. $)$ \\
\hline
\end{tabular}

\subsection{Meteorological Data}

This study considers the estimation of optimum collector area and WST volume of a FPC system in Adana, Turkey (Latitude 37. $0^{\circ} \mathrm{N} /$ Longitude $35.3^{\circ} \mathrm{E}, 20 \mathrm{~m}$ from sea level). For this purpose, the TMY for Adana was used to determine the optimum tilt angle and SWH system size. Hourly values of the TMY data for the selected location were obtained from the weather software Meteonorm 7.2.1 [13] and then added to the solar resource library of System Advisor Model (SAM) software [14] in the TMY2 weather file format (see Figure 3 for monthly average variation). 


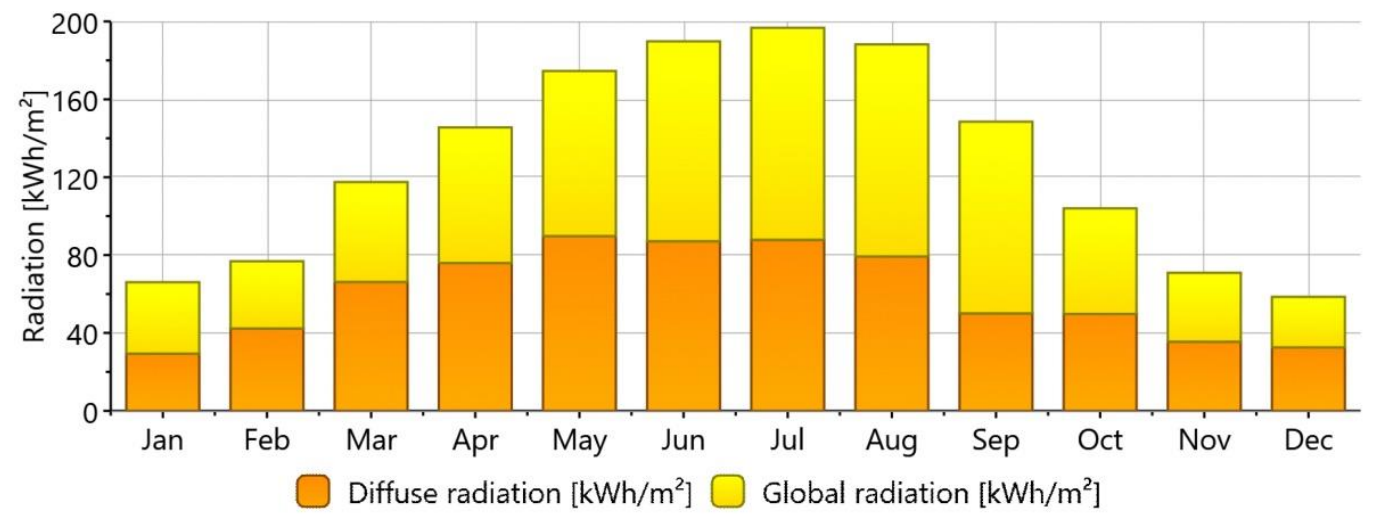

(a)

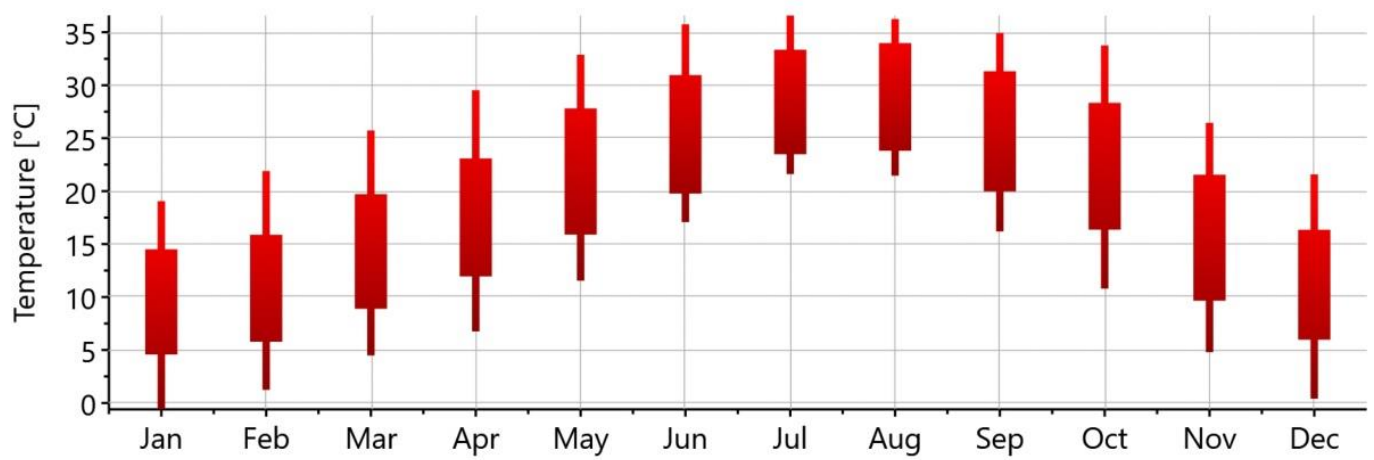

(b)

Figure 3. (a) Yearly variation of monthly average global radiation over the period of 1991-2010; (b) Yearly variation of monthly average ambient temperature over the period of 2000-2009 [13]

\subsection{Hot Water Consumption Profile}

In domestic applications, the hot water demand may vary during the course of time, i.e., day to day but mean daily load variations can be used for the prediction of long-term solar performance [15]. In this study, the Rand hot water profile shown in Figure 4 was used to estimate the daily hot water consumption throughout the simulated year. This load scheme is widely used in the literature and obtained by Fanney and Klein [16] as a result of monitoring six solar domestic hot water systems.

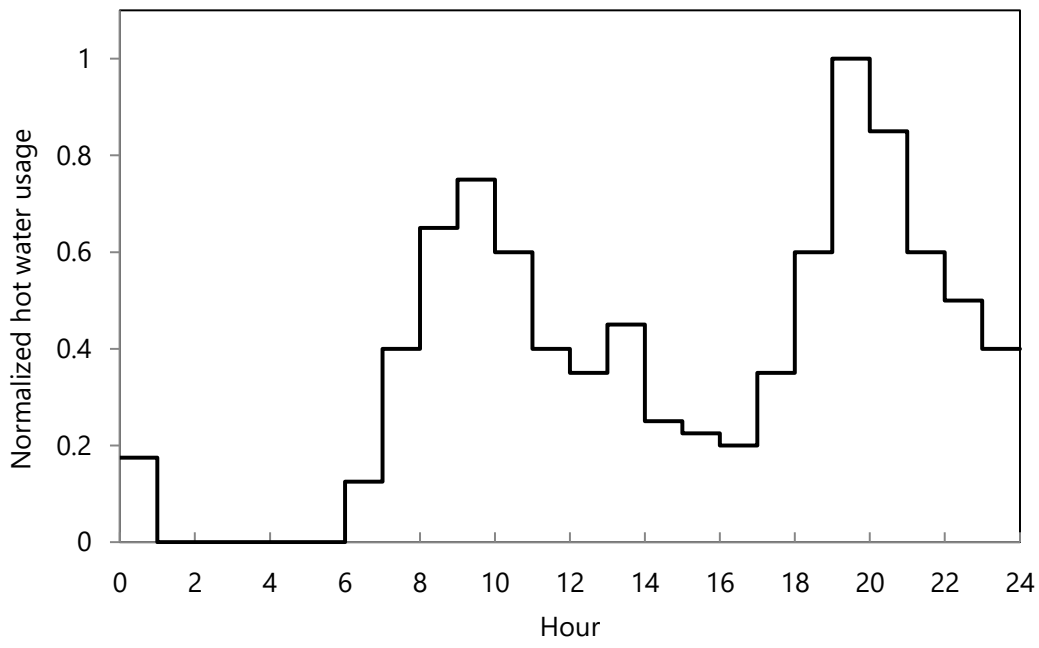

Figure 4. A normalized hot water use profile. Adapted from [17] 
Although different hot water consumption profiles are available in the literature, the influence of load distribution upon the performance of a SWH system is about $5 \%$ for the water storage tank capacity of $90 \mathrm{~L}$ per unit collector area [18]. This effect is somewhat larger when the storage capacity gets smaller.

\subsection{System Simulation and Model Description}

In this study, the National Renewable Energy Laboratory's SAM [14] was used to simulate the transient behavior of the SWH system shown in Figure 5. SAM yields very fast runtimes and good agreement on a time based analysis with much more detailed and validated simulations. The validation of the SWH model in SAM was performed by DiOrio et al. [19] with a commercially proven software TRNSYS [9].

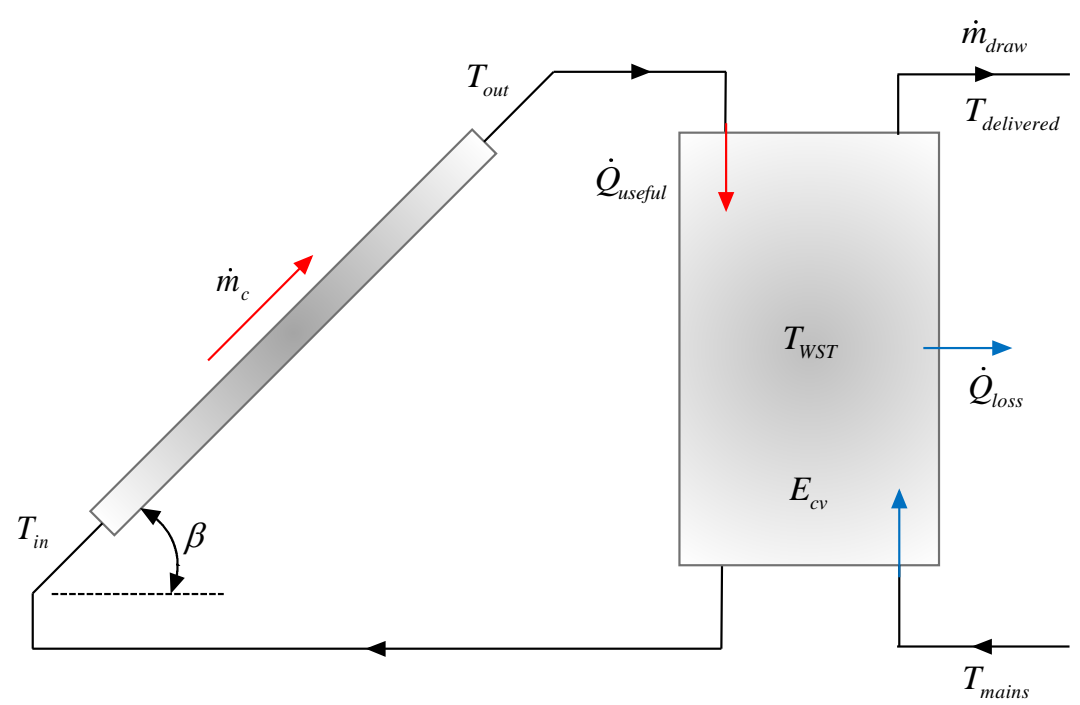

(a)

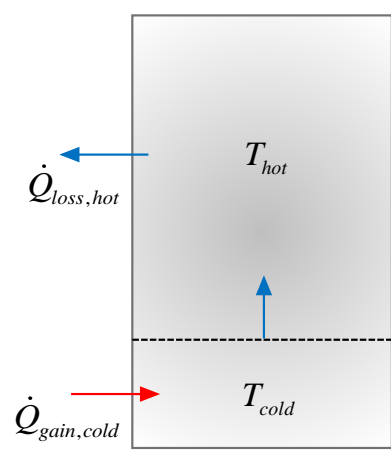

(b)

Figure 5. Representation of the domestic solar water heating system

The SAM model estimates the energy savings of the control volume, $E_{c v}$ (WST) using the first law of thermodynamics:

$$
\frac{\mathrm{d} E_{c v}}{\mathrm{~d} t}=\dot{Q}_{c v}+\dot{m}_{d r a w}\left(h_{\text {mains }}-h_{W S T}\right)
$$

where $c v$ refers to control volume, $\mathrm{d} E / \mathrm{d} t$ is the time rate of energy change, $\dot{Q}$ is the net rate of heat transfer, and the last term in the right-hand side of the equation corresponds to the net rate of energy transfer by the mass entering the WST at the mains temperature, $T_{\text {mains }}$ and leaving the WST at the mean tank temperature, $T_{W S T}$.

The energy of the control volume is equal to the internal energy of the water which is estimated by

$$
E_{c V}=\rho V_{W S T} c_{p} T_{W S T}
$$

where $\rho$ is the density of the water, $V_{W S T}$ is the volume of the WST, and $c_{p}$ is the specific heat of the water.

During solar collection, the WST is assumed to be uniform as shown in Figure 5a. Equation (1) is reduced to Eq. (3) to solve for the mean tank temperature in each hour: 


$$
\frac{\mathrm{d} T_{W S T}}{\mathrm{~d} t}=\frac{\dot{Q}_{u s e f u l}-\dot{Q}_{\text {loss }}+\dot{m}_{\text {draw }} c_{p}\left(T_{W S T}-T_{\text {mains }}\right)}{\rho V_{W S T} c_{p}}
$$

where $\dot{Q}_{\text {useful }}$ is the useful heat gain delivered to the collector fluid, and $\dot{Q}_{\text {loss }}$ is the heat loss from the WST to the ambient air at temperature $T_{a}$.

$$
\begin{gathered}
\dot{Q}_{\text {useful }}=F_{R} A_{c}\left[I_{T} K_{\tau \alpha}(\tau \alpha)_{n}-U_{L}\left(T_{i n}-T_{a}\right)\right] \\
\dot{Q}_{\text {loss }}=U_{W S T} A_{W S T}\left(T_{W S T}-T_{a}\right)
\end{gathered}
$$

where $F_{R}$ is the collector heat removal factor, $A_{c}$ is the collector area, $I_{T}$ is the radiation falling on tilted collector surface, $K_{\tau \alpha}$ is the incidence angle modifier, $(\tau \alpha)_{n}$ is the transmittance-absorbance product at normal incidence, $U_{L}$ is the overall collector heat loss coefficient, and $T_{i n}$ is the collector inlet temperature. $U_{W S T}$ and $A_{W S T}$ are the heat loss coefficient and the surface area of the WST.

In Eq. (4), the radiation falling on tilted surface is predicted using the Perez method which is summarized in [17]. The Perez model is more complex to use but agrees better with actual measurements as compared to the isotropic and HDKR methods. The incidence angle modifier (IAM) is defined as [17]

$$
K_{\tau \alpha}=\frac{(\tau \alpha)}{(\tau \alpha)_{n}}=1+b_{0}\left(\frac{1}{\cos \theta}-1\right)
$$

where $b_{0}$ is the IAM coefficient given in Table, and $\theta$ is the angle of incidence. Eq. (6) can be used to estimate the modifiers at angles less than or equal to $70^{\circ}$.

In Eq. (5), the ambient temperature during a full year simulation is estimated to be constant at an average temperature obtained from Figure 3 for heat loss calculations of the WST tank.

Once useful solar energy is not being collected, i.e. during night, the tank is assumed to be stratified into one hot node and one cold node [19] as shown in Figure 5b. In this condition, the volumes of hot and cold regions ( $V_{\text {hot }}$ and $V_{\text {cold }}$ ) vary with water draws according to the need. The cold volume continues to increase and the hot volume decreases until solar collection begins again. The resulting temperature equations in differential forms are derived respectively for the hot and cold node temperatures as

$$
\begin{gathered}
\frac{\mathrm{d} T_{\text {hot }}}{\mathrm{d} t}=\frac{-\dot{Q}_{\text {loss } h o t}}{\rho V_{\text {hot }} c_{p}} \\
\frac{\mathrm{d} T_{\text {cold }}}{\mathrm{d} t}=\frac{\dot{Q}_{\text {gain, cold }}+\dot{m}_{\text {draw }} c_{p}\left(T_{\text {mains }}-T_{\text {cold }}\right)}{\rho V_{\text {cold }} c_{p}}
\end{gathered}
$$

The solar fraction, $f$ is the key parameter for the maximization of energy savings. It specifies the ratio of how much solar energy collected by the WST to how much total energy needed to supply the delivery temperature with auxiliary heater as below.

$$
f=\frac{\dot{Q}_{\text {saved }}}{\dot{Q}_{\text {needed }}}=\frac{\dot{m}_{\text {draw }} c_{p}\left(T_{\text {set }}-T_{\text {mains }}\right)-\dot{m}_{\text {draw }} c_{p}\left(T_{\text {set }}-T_{\text {delivered }}\right)}{\dot{m}_{\text {draw }} c_{p}\left(T_{\text {set }}-T_{\text {mains }}\right)}
$$

where $T_{\text {set }}$ is the mean value of delivery set temperature in domestic usage, and $T_{\text {delivered }}$ is the delivery temperature supplied by the WST tank at the hour interested. 
It is noted that for calculating the optimum SWH size, maximization of the solar fraction was considered through the analyses.

\subsection{SAM Interface and Solution Algorithm}

SAM has a simulation interface which simplifies the analysis and helps users to integrate simulation parameters easily. The following flow diagram shown in Figure 6 presents the simulation steps used for this study on SAM.

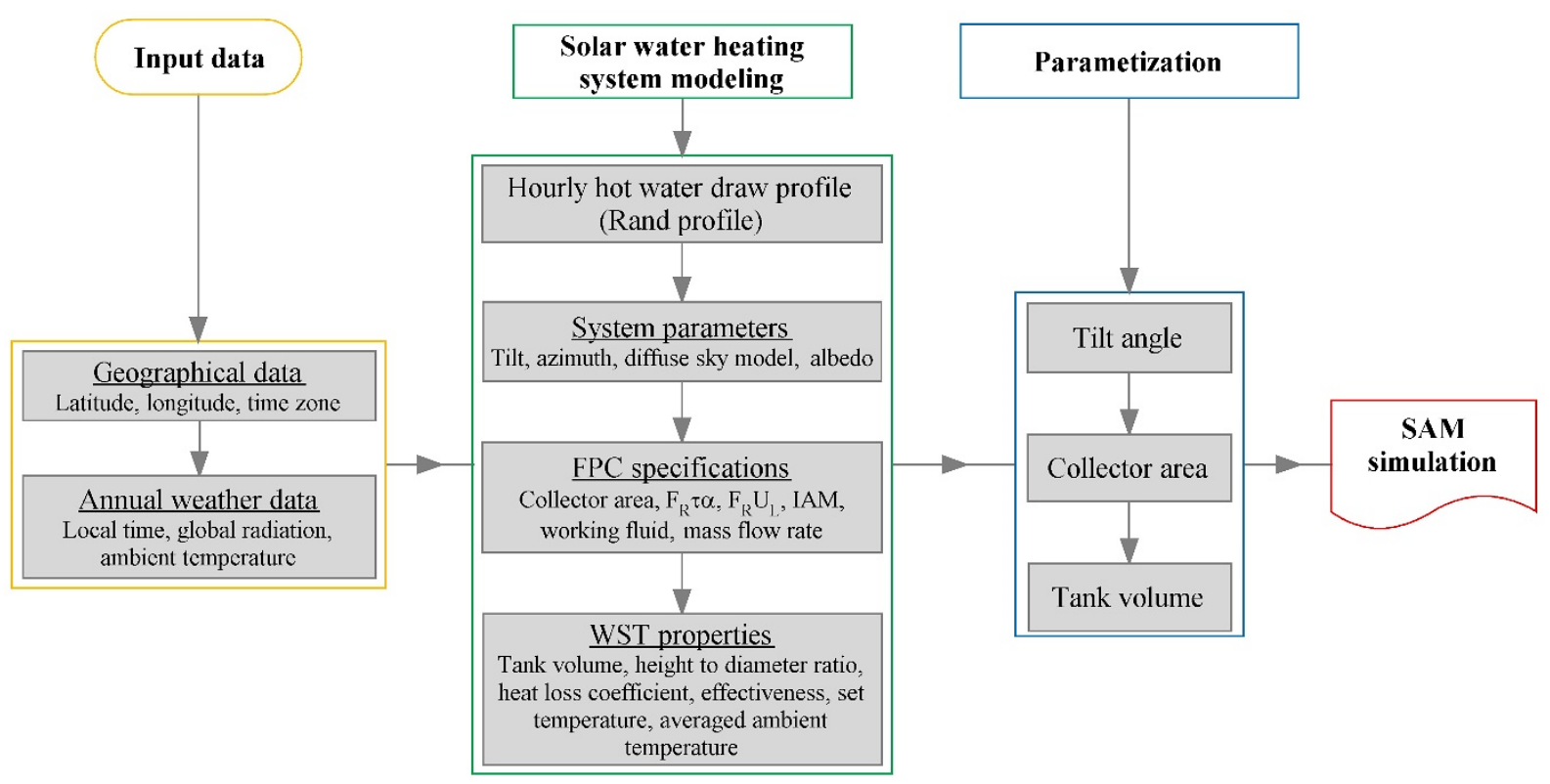

Figure 6. SAM's solution approach for the SWH system

\section{RESULTS AND DISCUSSION}

Based on the methodology presented above, the simulation modeling constructed in SAM has computed the outputs for the system in Adana, Turkey. The several simulation parameters of the system, $\beta=35.0^{\circ}, A_{c}=3 \mathrm{~m}^{2}, V_{W S T}=120 \mathrm{~L}, U_{W S T}=1 \mathrm{~W} / \mathrm{m}^{2} .{ }^{\circ} \mathrm{C} T_{\text {set }}=50^{\circ} \mathrm{C}$, the domestic hot water consumption $=140 \mathrm{~L} /$ day, were specified to be invariable unless the contrary is revealed. The calculations were made for a south-facing FPC for the full year round since the optimum orientation for solar collectors is south facing in the northern hemisphere [17].

The variation of the solar fraction at varying tilt angle is indicated in Figure 7 . The optimum angle yielding the greatest energy harvesting for the location is calculated to be $35.0^{\circ}$. This value was compared with the results available in the literature $[4,5,20]$. Nijegorodor et al. [20] derived a set of relations for any location which lies between a latitude of $60^{\circ}$ south to $60^{\circ}$ north. As the relations are applied for Adana, the optimum tilt angle is found to be $35.2^{\circ}$. Gunerhan and Hepbasli [4] presented that the optimum tilt angle for a solar system operating throughout a year is taken to be equal to the latitude of the location, i.e. $37.0^{\circ}$. Bakirci [5] calculated the optimum tilt angles for maximizing the values of monthly average daily global radiation. The optimum tilt angle has been found to be $31.2^{\circ}$ after averaging the monthly optimum tilt angles. It is clearly seen that the result obtained from the simulation is in good agreement with the literature. It is proposed that the tilt angle of the collector should be taken between the range of "the latitude of the location -15 or +15 " by this way the solar fraction becomes $2.7 \%$ lower than the maximum solar fraction obtained at the utmost limits. 


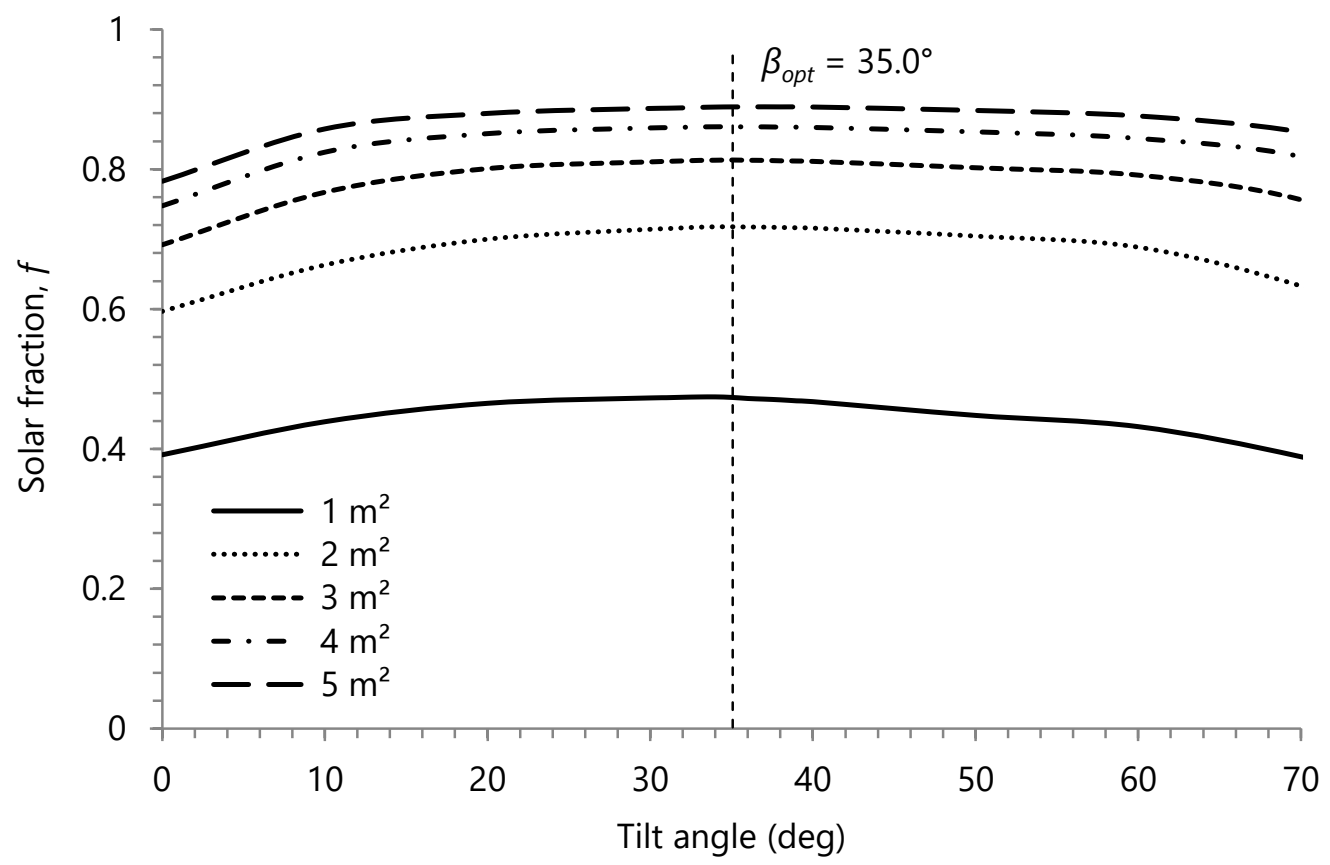

Figure 7. Variation of solar fraction with collector tilt angle

The influence of the collector area on the solar fraction based on the variation in the WST volume is shown in Figure 8. The system without WST produces much lower solar fractions around 0.32-0.40. Increasing the WST size improves the solar fraction but the size greater than $100 \mathrm{~L}$ has little influence on it. This means that enlarging the WST size after this critical value will increase the system size and be costlier. On the other hand, increasing the collector size is pretty effective on the solar fraction since the collective energy to meet the delivery load is increased. At $1 \mathrm{~m}^{2}$, increasing the WST volume lowers the solar fraction due to higher heat losses from the larger tank surface areas. Increasing the collector area has enhanced remarkably the solar fraction but its rise decreases gradually after $3 \mathrm{~m}^{2}$. As a common practice, most of the collector producers in Adana set up the collector systems benightedly with a collector area of $3.5 \mathrm{~m}^{2}$ and a WST of $160 \mathrm{~L}$ for the dwellings featuring 4 occupants. As seen, the collector areas yielded from the practice and the simulation are close to each other but the difference between the storage volumes is quite wide. In practical applications, increasing the WST volume may lead to increase the mass of hot water in the WST but this lowers the averaged WST temperature (increases the heat loss from the WST due to enlarged surface area, as well) especially in cold days and accordingly increases the auxiliary heating power which, in turn, lowers the annual solar fraction. The simulation results clearly indicate that the size of the practical systems is larger than the optimum values obtained here but should be reviewed from the view of cost reduction.

The influence of the delivery set temperature on the solar fraction is shown in Figure 9. In many studies and publications of organizations, the usable hot water temperature is recommended to be between the ranges of $45-60{ }^{\circ} \mathrm{C}$. For example, the mean value of delivery set temperature in domestic usage was reported to be $51.9 \pm 1.3{ }^{\circ} \mathrm{C}$ by Energy Saving Trust [21]. Therefore, the delivery temperature ranging from $40{ }^{\circ} \mathrm{C}$ to $60^{\circ} \mathrm{C}$ was analyzed. As it is shown previously, increasing the WST volume beyond $100 \mathrm{~L}$ is not an effective way to increase the solar fraction. Increasing the set temperature causes higher tank temperature which results in increased thermal loss from the tank and warmer water entering the collector and accordingly lower collector efficiency and solar fraction. It is inferred that for each $5{ }^{\circ} \mathrm{C}$ increment in the set temperature results in approximately $4 \%$ drop in the solar fraction. 
Yılmaz / Anadolu Univ. J. of Sci. and Technology A-Appl. Sci. and Eng. 19(1)-2018

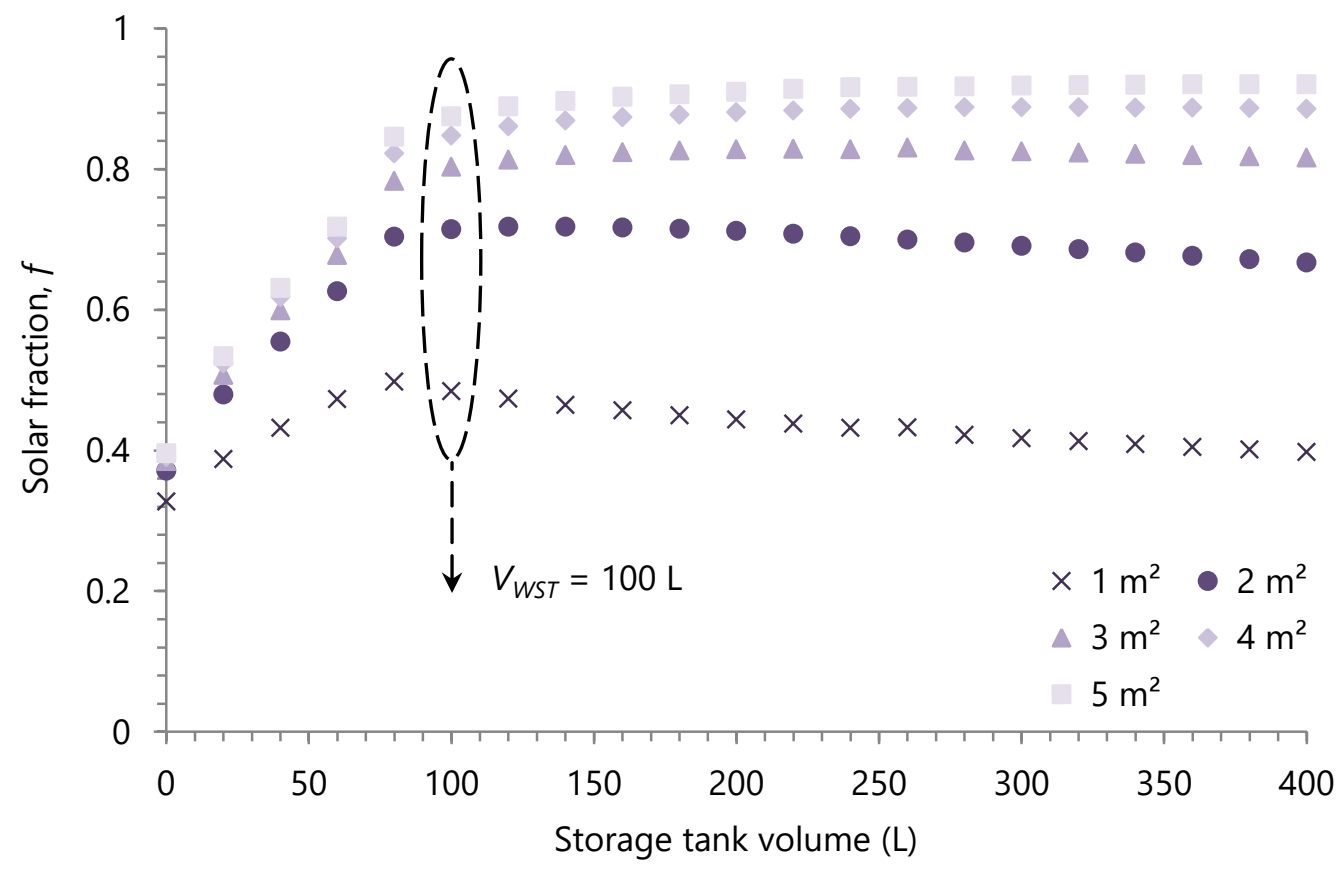

Figure 8. Effect of WST volume on solar fraction for different collector areas

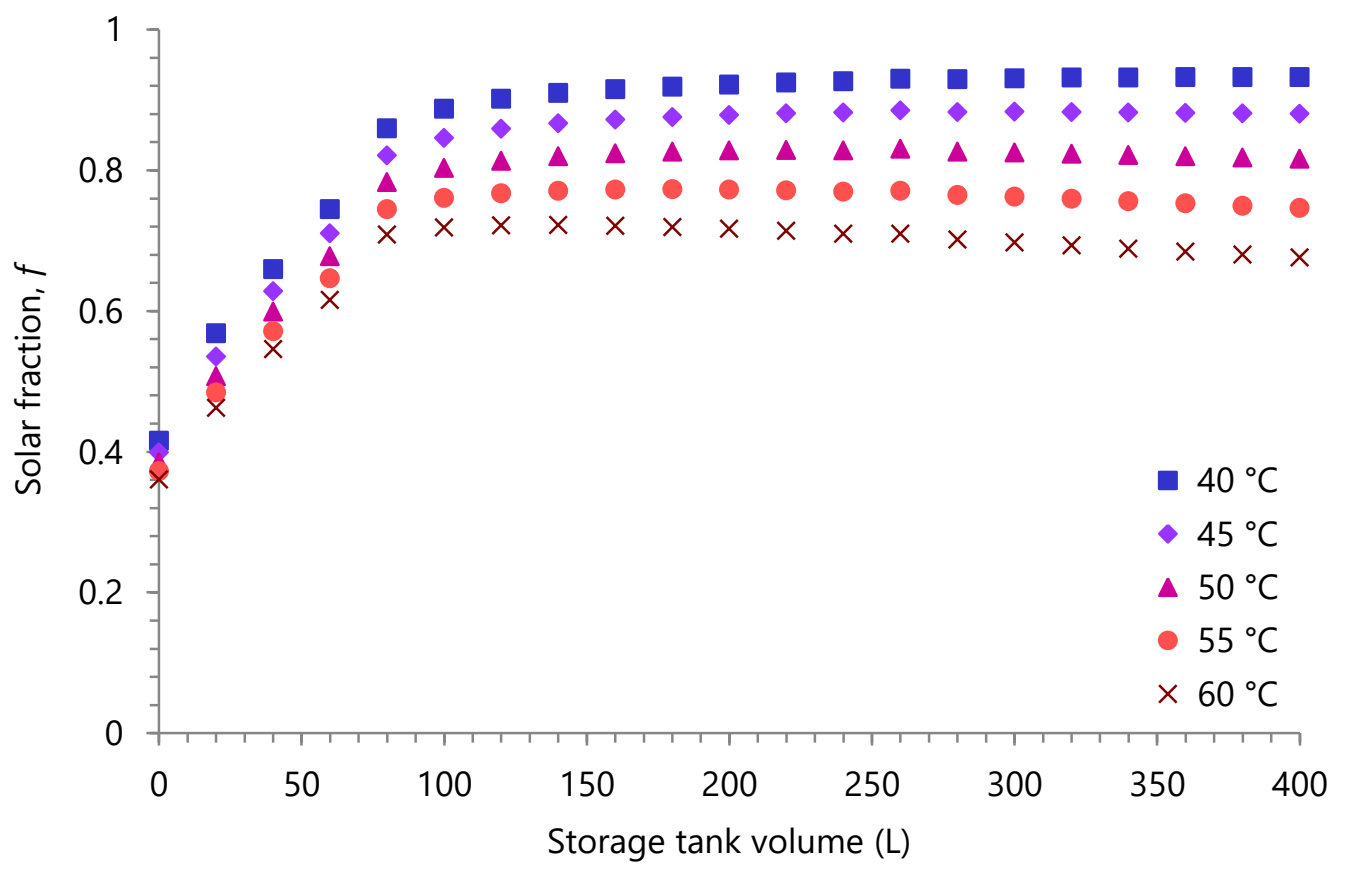

Figure 9. Effect of delivery set temperature on solar fraction for different WST volumes

In the simulation, the transient performance of the SWH system was also calculated under different daily hot water consumption ranging from $100-180 \mathrm{~L}$ as shown in Figure 10. The mean household consumption was found to be $122 \pm 18 \mathrm{~L}$ /day with the statistical analysis made by Energy Saving Trust [21]. This value can vary depending on the number of occupants living in a dwelling. For this reason, the variation of the daily hot water consumption was analyzed and presented here. As can be seen clearly, lowering daily hot water consumption increases the solar fraction to high levels. This may enable to have lower collector area in case the daily hot water demand i.e., number of occupants is 
low. It is also shown that for each $20 \mathrm{~L} /$ day increment in the daily hot water consumption results in approximately $3 \%$ drop in the solar fraction.

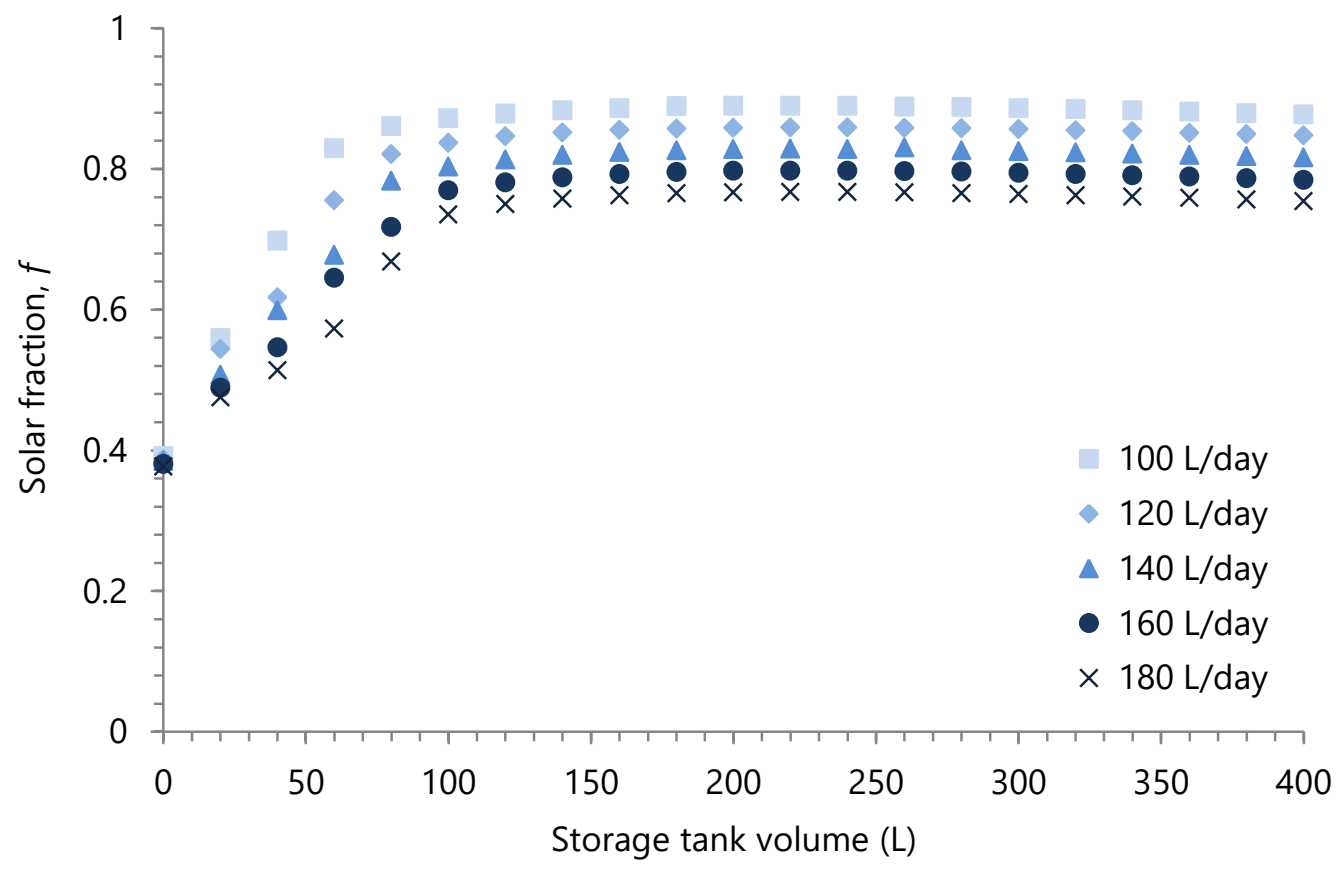

Figure 10. Effect of daily hot water usage on solar fraction for different WST volumes

\section{CONCLUSIONS}

In this paper, the optimum orientation and sizing of a thermosyphon SWH system consisted of a FPC and WST were determined using the TMY data for Adana. All the efforts presented here will play important role in improving the performance of the SWH system and its cost decrement with proper selection of system size. The following conclusions may be drawn from the results of the present study:

- The best orientation for increasing the solar harvesting of a SWH system in Adana is recommended to be $35.0^{\circ}$ tilt angle. The optimum tilt in the range of the latitude minus $20^{\circ}$ to the latitude plus $20^{\circ}$ has relatively little effect on the annual solar fraction.

- The SWH system without WST yields solar fractions around 0.32-0.40. Adding a WST improves the solar fraction but it has little effect for the size greater than $100 \mathrm{~L}$.

- Increasing the collector area improves the solar fraction remarkably but its rise decreases gradually after $3 \mathrm{~m}^{2}$.

- For each $5{ }^{\circ} \mathrm{C}$ increment in the delivery set temperature results in approximately $4 \%$ drop in the annual solar fraction.

- For each $20 \mathrm{~L} /$ day increment in the daily hot water consumption results in approximately $3 \%$ drop in the annual solar fraction.

- The results presented here will provide SHW manufacturers or installers to specify optimum orientation and sizing of FPC based domestic hot water systems. 
Yllmaz / Anadolu Univ. J. of Sci. and Technology A-Appl. Sci. and Eng. 19(1)-2018

\section{ACKNOWLEDGEMENTS}

The weather data support received from the team member of Meteotest, Mr. Jan Remund is duly acknowledged and appreciated.

\section{REFERENCES}

[1] The Solar Hot Water Heater - A Brief Trip Through Time, <http://www.solarhotwatersystems.com/the-solar-hot-water-heater-a-brief-trip-through-time/>. [accessed 21.08.2017].

[2] Mauthner F, Weiss W, Spörk-Dür M. Solar Heat Worldwide: Markets and Contribution to the Energy Supply 2014. International Energy Agency-Solar Heating and Cooling Program, 2016.

[3] Ulgen K. Optimum tilt angle for solar collectors. Energ Source Part A 2006; 28: 1171-1180.

[4] Gunerhan H, Hepbasli A. Determination of the optimum tilt angle of solar collectors for building applications. Build Environ 2007; 42: 779-783.

[5] Bakirci K. General models for optimum tilt angles of solar panels: Turkey case study. Renew Sust Energ Rev 2012; 16: 6149-6159.

[6] Ertekin C, Kulcu R, Evrendilek F. Techno-economic analysis of solar water heating systems in Turkey. Sensors 2008; 8: 1252-1277.

[7] ArcGIS, <http://www.esri.com/>. [accessed 21.08.2017].

[8] Akinoğlu B, Shariah A, Ecevit A. Solar domestic water heating in Turkey. Energy 1999; 24: 363374.

[9] TRaNsient SYstems Simulation Program, <http://sel.me.wisc.edu/trnsys>. [accessed 21.08.2017].

[10] Çomaklı K, Çakır U, Kaya M, Bakirci K. The relation of collector and storage tank size in solar heating systems. Energ Convers Manage 2012; 63: 112-117.

[11] Hasan A. Thermosyphon solar water heaters: effect of storage tank volume and configuration on efficiency. Energ Convers Manage 1997; 38: 847-854.

[12] SRCC Certification, Rating \& Listing Directory, <http://solarrating.org/certification_listing_directory/index.html>. [accessed 21.08.2017].

[13] Meteonorm, <http://www.meteonorm.com/en/>. [accessed 21.08.2017].

[14] System Advisor Model (SAM), <https://sam.nrel.gov/>. [accessed 21.08.2017].

[15] Shariah A, Löf G. The optimization of tank-volume-to-collector-area ratio for a thermosyphon solar water heater. Renew Energ 1996; 7: 289-300.

[16] Fanney A, Klein S. Performance of solar domestic hot water systems at the national bureau of standards-measurements and predictions. J Sol Energ-T ASME. 1983; 105: 311-321.

[17] Duffie JA, Beckman WA. Solar Engineering of Thermal Processes. 4th ed. John Wiley \& Sons, 2013. 
Yılmaz / Anadolu Univ. J. of Sci. and Technology A-Appl. Sci. and Eng. 19(1)-2018

[18] Gutierrez G, Hincapie F, Duffie J, Beckman W. Simulation of forced circulation water heaters; effects of auxiliary energy supply, load type and storage capacity. Sol Energy 1974; 15: 287-298.

[19] DiOrio N, Christensen C, Burch J, Dobos A. Technical manual for the SAM solar water heating model. National Renewable Energy Laboratory (NREL), 2014.

[20] Nijegorodov N, Devan K, Jain P, Carlsson S. Atmospheric transmittance models and an analytical method to predict the optimum slope of an absorber plate, variously oriented at any latitude. Renew Energ 1994; 4: 529-543.

[21] Measurement of domestic hot water consumption in dwellings. Energy Saving Trust, England, 2008. 